\title{
Adaptações para Osteoartrite de Mãos
}

\section{Assistive Devices for Hand Osteoarthritis}

\author{
Johanna Noordhoek ${ }^{(1)}$, Aline Torquetti ${ }^{(2)}$
}

Considerando que pessoas com osteoartrite (OA) nas articulações das mãos experimentam dificuldades na execução de tarefas manuais, foram selecionadas possibilidades de adaptações que objetivam auxiliar o desempenho da escrita, a manipulação de chaves e a tarefa de abotoar roupas (Figuras 1, 2 e 3).

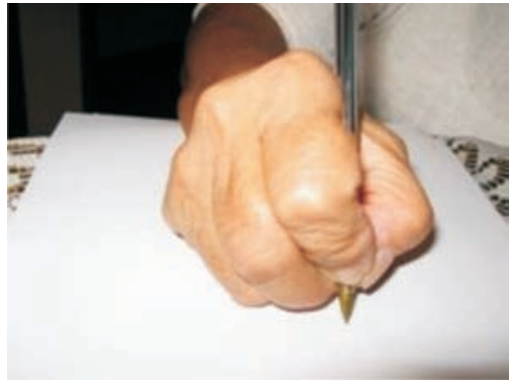

Figura 1 - Indivíduo com 0A, executando a tarefa de escrita sem adaptação.

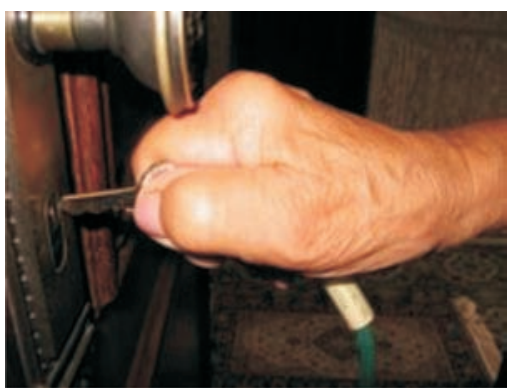

Figura 2 - Indivíduo com 0A, executando a tarefa de abrir porta sem adaptação.

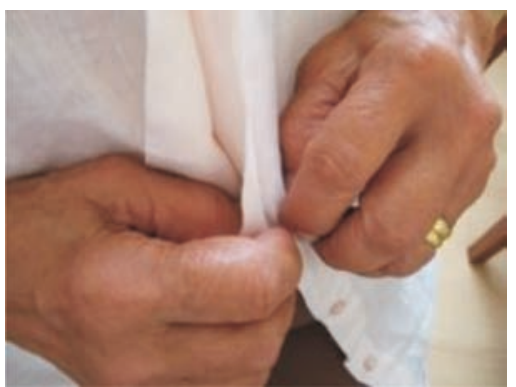

Figura 3 - Indivíduo com 0A, executando a tarefa de abotoar camisas sem adaptação.

A adaptação de canetas é feita com o papel reciclável tipo machê (Figura 4). A adaptação de chaves é realizada modelando-se gesso, formando um cone que envolve a superfície de estabilização da chave (Figura 5). Depois da secagem do gesso, pode-se envolver a adaptação com algum tecido para dar mais aderência e conforto durante o uso. O abotoador de camisas é confeccionado com um pedaço de arame de média espessura, modelado em forma de trevo (Figura 6), fixado em um rolo de papel machê, que é posteriormente envolvido por tecido.

As três adaptações são produzidas em material leve, o que auxilia a compensação de fraquezas musculares. Esses materiais são texturizados, gerando fricção entre a superfície do objeto e a mão, tornando uma preensão fraca mais eficiente. O engrossamento dos cabos oferece maior área para apoio dos dedos, promovendo estabilidade

Declaramos a inexistência de conflitos de interesse.

1. Professora do Departamento de Terapia Ocupacional da Escola de Educação Física, Fisioterapia e Terapia Ocupacional da Universidade Federal de Minas Gerais (UFMG) e coordenadora do Projeto de Extensão "Grupo de Orientação aos Indivíduos Acometidos por Doenças Reumáticas".

2. Acadêmica do curso de Terapia Ocupacional da UFMG

Endereço para correspondência: Professora Johanna Noordhoek, Rua Mármore, 362/404, Santa Teresa, 31010-220, Belo Horizonte, MG, e-mail: johannanoord@yahoo.com.br 
para a manipulação do objeto, auxiliando na diminuição da dificuldade de coordenação, na redução do esforço articular e na limitação de movimentos indesejáveis (Figuras 7, 8 e 9).

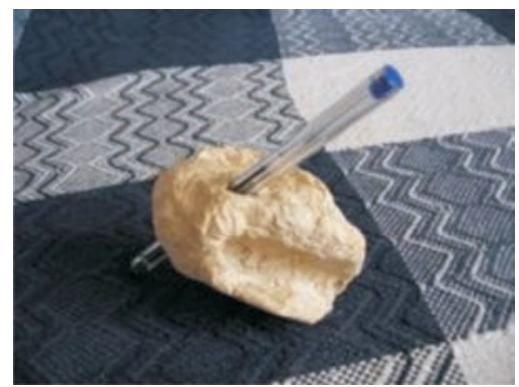

Figura 4 - Vista superior da adaptação para a escrita.

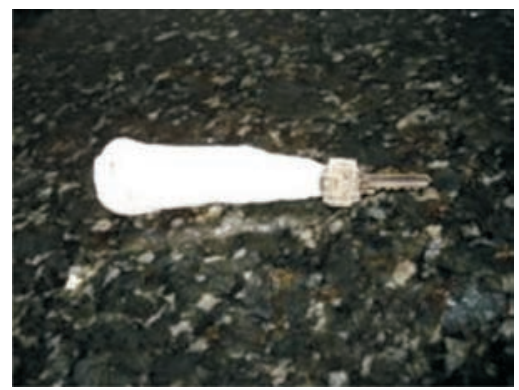

Figura 5 - Vista superior da adaptação para chave.

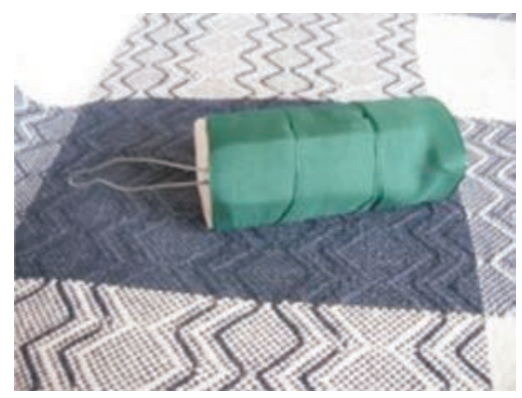

Figura 6 - Vista superior da adaptação para abotoadura.

\section{REFERÊNCIAS}

1. Burkholder JF: Osteoarthritis of the hand: a modifiable disease. J Hand Theray 79-89, 2000.
Essas adaptações contribuem para a melhora da qualidade de vida dos indivíduos com OA, facilitando o desempenho de tarefas diárias, que serão executadas com maior conservação de energia e redução de sintomas, prevenindo deformidades.

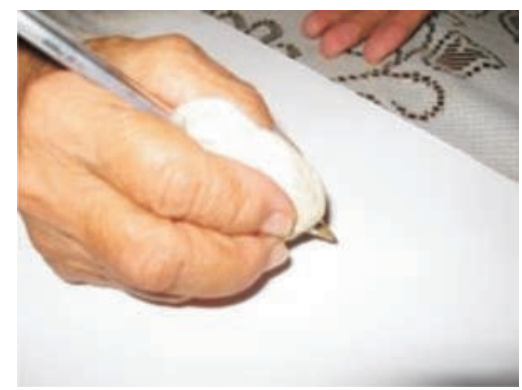

Figura 7 - Execução da tarefa com uso da adaptação.

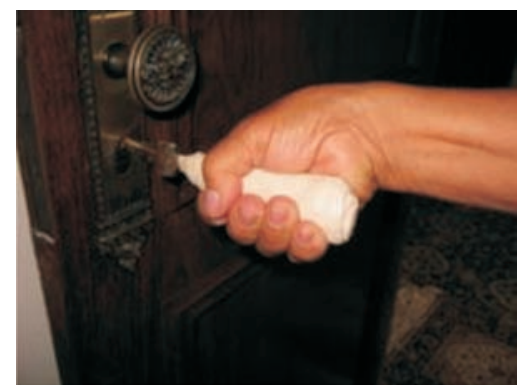

Figura 8 - Execução da tarefa com uso da adaptação.

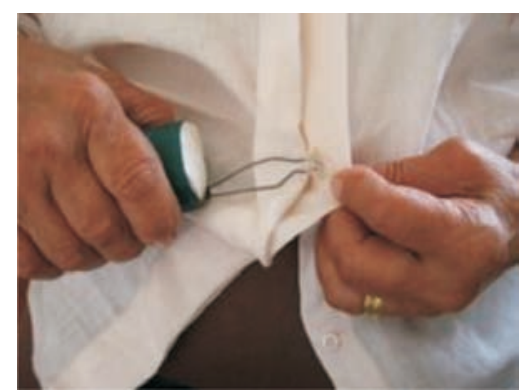

Figura 9 - Execução da tarefa com uso da adaptação.

2. Trombly C:Terapia ocupacional para disfunções físicas. Rio de Janeiro: Santos Editora, 2005.

3. Stanley BG; Tribuzi SM: Concepts in hand rehabilitation. USA: Davis Company, 1992. 